\title{
The effect of nutritional protocols on mechanically ventilated patients in intensive care unit: A randomised controlled study
}

\author{
Shipra Singh ${ }^{1}$, Suruchi Ambasta ${ }^{2, *}$ \\ Assistant professor, Dept. of Anaesthesiology and Critical Care, Mayo Institute of Medical Sciences, Barabanki, \\ Uttar Pradesh, India \\ *Corresponding Author: \\ Email: suruchi0904@gmail.com
}

Received: $20^{\text {th }}$ February, 2018

Accepted: $16^{\text {th }}$ April, 2018

\begin{abstract}
Introduction: Critically ill patients are prone to develop malnutrition which is a major contributory factor to the already existing burden of morbidity and mortality. Early nutrition support is an effective therapy to prevent malnutrition when patients are unable to take oral nutrition.

Aim: To determine the effectiveness of a nutrition support protocol versus non-protocol management on initiating nutrition support in ICU patients.

Materials and Methods: This randomized controlled study was conducted on fifty critically ill patients on mechanical ventilation with twenty five patients in each group. Nutrition protocols were followed in Group I patients and group II comprised of nonprotocolised patients.

Results: Hospital stay for group I patients was 22.7 days while group II patients stayed for 31.9 days (p-value $<0.001$ ). Significant reduction of 8 days in ICU stay was noted in group I patients as compared to group II (p-value <0.001). The duration of mechanical ventilation was reduced by 7 days in group I patients ( $<<0.001)$. Mortality rate was $48 \%$ in group II as compared to $28 \%$ in group I. Nutrition could be initiated 16 hours earlier in group I patients.

Conclusion: Patients in whom nutrition support protocols were followed received enteral nutrition earlier, had early weaning from ventilator, spent less time in ICU as well as hospital and had lesser complications with low mortality.
\end{abstract}

Keywords: Enteral nutrition, Nutrition protocol, Malnutrition, Mechanical ventilation, ICU.

\section{Introduction}

Malnutrition in critically ill patients is quite common and leads to increased morbidity and mortality. At admission, $43 \%$ of patients are found to be seriously malnourished while $65 \%$ are prone to malnutrition. ${ }^{1,2}$ Malnutrition leads to prolonged intensive care unit (ICU) stay and increased incidence of infection signifying overall decreased health of the patients. ${ }^{3,4}$ Previous studies indicate that initiating nutrition support within $48 \mathrm{hrs}$ of ICU admission decreases the catabolic response, hastens wound healing and reduces morbidity due to sepsis..$^{3-5}$

Enteral nutrition (EN) has been proven to be advantageous over parenteral nutrition or prolonged starvation in critically ill patients ${ }^{6,7}$ as it improves wound healing due to better collagen synthesis and promoting gastrointestinal mucosal integrity. It is also cost-effective as compared to other nutritional modes. Higher incidences of infection rate, metabolic disturbance and disuse atrophy of the bowel have been observed with parenteral nutrition. ${ }^{4,10}$

Enteral nutrition during early hours after admission is advised to minimize the unwanted side effects of starvation. ${ }^{1,5,14}$ Studies have proven that protocolized enteral feeding improves patient outcome and reduces complications. ${ }^{6,14}$ Though many studies have emphasized the importance of early nutrition, none of them have clearly stated how to achieve these recommendations. ${ }^{8,9,15}$ This study aims to determine whether implementation of a nutrition support protocol may hasten time to nutrition initiation and help to achieve better outcomes.

\section{Aims and Objectives}

Primary Aim: To determine the effectiveness of a nutrition support protocol versus non-protocol management on initiation of nutrition support in ICU patients.

Secondary Aim: To observe the effect of nutrition protocol on mortality, complications, and ICU stay.

\section{Materials and Methods}

Study Design: This randomized controlled study was conducted on ICU patients under controlled ventilation in a medical college hospital over a period of twelve months. Randomization was done by chit in box technique.

Ethical committee approval was obtained. Following written informed consent the study was conducted on critically ill, both surgical and nonsurgical patients on mechanical ventilation admitted to ICU under the Department of Anaesthesia and comprised of 50 cases.

Inclusion Criteria: The study included critically ill intubated patients of either sex over 16 years, likely to be admitted to ICU for more than 48 hours and unable to take oral diet. Medical patients (COPD, chronic kidney disease, poisoning), pre and post surgical patients 
(obstetric, general surgery, orthopedics) comprised our study.

Patients with intestinal obstruction, gastrointestinal bleeding, ischemia or inflammation, vomiting and diarrhea, fistulas, diffuse peritonitis were excluded from the study.

Methodology: Baseline investigations done before study were blood sugar, serum electrolytes, serum albumin, blood urea and total leucocyte counts. Investigations during the study were blood sugar every 6 hourly, total leucocyte count daily, serum electrolytes and blood urea every alternate day, serum albumin weekly.

A total of 50 patients were selected for the study and were randomly allotted into two groups. Group I consisted 25 patients in whom evidence-based standard nutrition support protocols were followed. Group II consisted of 25 patients in whom nutrition support protocols were not followed but standard physician managed care was given as routinely followed in ICU.

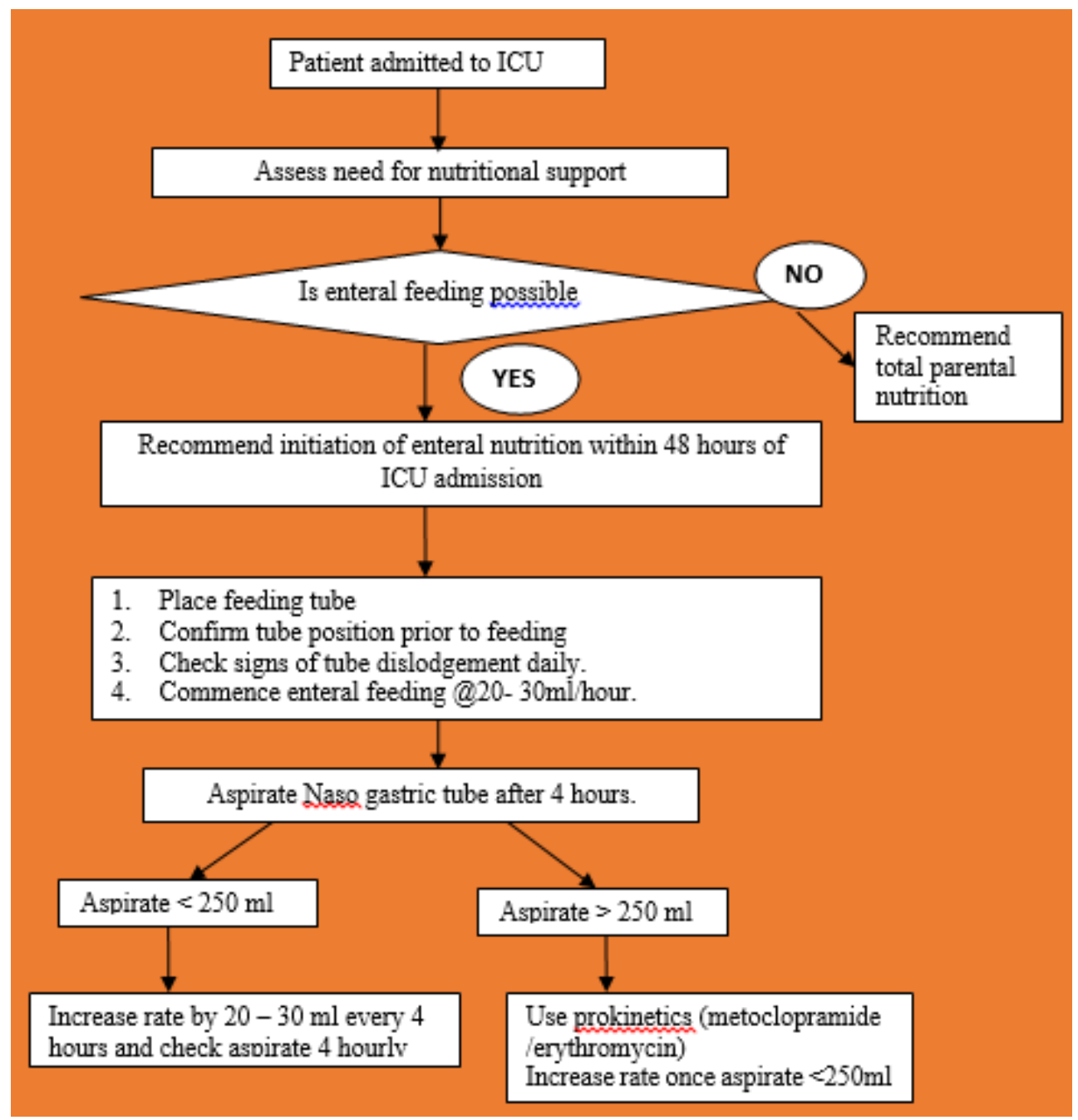

\section{Fig. 1 : Study protocol}

The data collected included age, gender, admission category (surgical vs medical), height, weight of each patient. Nutrition information, blood glucose levels, total insulin dose, supplemental glutamine and the use of prokinetic drugs was recorded daily. Blood sugar was maintained between $80-120 \mathrm{mg}$ percent with the help of regular insulin as per sliding scale. Calculation of nutrition was done as per the guidelines shown below.

\section{Calculation of required nutrition (per $\mathrm{kg}$ of normal weight)}

\begin{tabular}{|l|c|}
\hline Fluids & 20-40ml (plus fluid loss equivalent to urine and perspiration \\
\hline Energy & $25-35 \mathrm{kcal}$ \\
\hline Protein & $1-1.5 \mathrm{gm}$ \\
\hline Fat & $0.5-1.5 \mathrm{gm}$ \\
\hline Carbohydrates & $0.3 \mathrm{gm} / \mathrm{kg} / \mathrm{hr}$ \\
\hline
\end{tabular}


The parameters recorded were total hours from admission to the initiation of nutrition, days of mechanical ventilation, ICU and in hospital stay and the complications in each group. Daily information was collected for a period of 14 days unless death or ICU discharge occurred. Patients were followed up for a maximum period of 60 days.

Ethical Aspects: The study protocol was approved by Institute Ethical committee.

Statistical Study: Statistical package for the social sciences version 18 (SPSS) for windows was used for the analysis of the recorded data. Additional to the descriptive statistical methods (Mean, Standard deviation), Student t-test was used for the comparison of quantity of the parameters among groups. Repeated measures data were analysed by ANOVA (analysis of variance); differences from the basal values were analysed by Bonferroni method, paired sample t-test.

\section{Results}

Major proportion of study group belonged to 20-50 years of age. No significant demographic variations were observed between the two groups $(p$-value $=0.88)$. (Table 1)

Table 1: Demographic variables

\begin{tabular}{|l|c|c|c|}
\hline & Group I & Group II & P value \\
\hline Mean age & $41.66 \pm 19.28$ & $40.88 \pm 18.59$ & 0.88 \\
\hline Sex (M: F) & $1.5: 1$ & $2.12: 1$ & $>0.05$ \\
\hline Mean weight & $50.04 \pm 10.52$ & $48.64 \pm 8.55$ & 0.60 \\
\hline Mean length & $155.08 \pm 10.6$ & $153.88 \pm 10.98$ & 0.69 \\
\hline BMI $(\mathrm{Kg} / \mathrm{m}$ & $20.82 \pm 8.2$ & $20.77 \pm 8.9$ & 0.988 \\
\hline
\end{tabular}

Table 2: Impact of feeding protocols

\begin{tabular}{|c|c|c|c|}
\hline & \multicolumn{2}{|c|}{ Bedside feeding protocol } & \multirow[t]{2}{*}{ P value } \\
\hline & Yes (group I) & No (group II) & \\
\hline No. of patients & 25 & 25 & \\
\hline Medical & 2 & 3 & \\
\hline Surgical-elective & 4 & 6 & \\
\hline Surgical emergency & 11 & 10 & \\
\hline Trauma & 8 & 6 & \\
\hline $\begin{array}{l}\text { ICU admission to initiation of enteral nutrition } \\
\text { (in hours) }\end{array}$ & $41.2( \pm 8.5)$ & $57.1( \pm 18.8)$ & $<0.001$ \\
\hline Mechanical ventilation (in days) & $10.1( \pm 3.6)$ & $18( \pm 4.1)$ & $<0.0001$ \\
\hline ICU stay (in days) & $17.26( \pm 5.3)$ & $25.11( \pm 8.5)$ & $<0.0001$ \\
\hline Hospital stay (in days) & $22.7( \pm 7.5)$ & $31.9( \pm 9.8)$ & $<0.0001$ \\
\hline Mortality (within 60 days) & $7(28 \%)$ & $12(48 \%)$ & $<0.0001$ \\
\hline
\end{tabular}

Enteral nutrition could be initiated earlier in group I (41.2 \pm 8.5$)$ hours as compared to group II $(57.1 \pm 18.8)$. ICU stay in group I was $17.26( \pm 5.3)$ days while in group II it was $25.11( \pm 8.5)$ days, (p-value <0.001) which showed a reduction of about 8 days. Hospital stay in group I patients was $22.7( \pm 7.5)$ days while in group II patients it was 31.9( \pm 9.8$)$ days which showed decreased stay in group I patients. A total of 7 patients died in group I while 12 patients out of group II died within 60 days which showed overall low rate of mortality in group I. (Table 2)

Table 3: Complications

\begin{tabular}{|l|c|c|c|}
\hline \multicolumn{1}{|c|}{ Complications } & $\begin{array}{c}\text { Group I } \\
\text { number (percentage) }\end{array}$ & $\begin{array}{c}\text { Group II } \\
\text { Number (percentage) }\end{array}$ & P value \\
\hline Septicemia & $2(8 \%)$ & $7(28 \%)$ & $<0.05$ \\
\hline Chest related & $5(16 \%)$ & $13(52 \%)$ & $<0.05$ \\
\hline Urinary tract infections (UTI) & $1(4 \%)$ & $5(20 \%)$ & $<0.05$ \\
\hline Enteric & $6(24 \%)$ & $5(20 \%)$ & $>0.05$ \\
\hline
\end{tabular}

The incidence of septicemia ( 2 in group I, 7 in group II), respiratory infections ( 5 in group I, 13 in group II) and UTI ( 1 in group I, 5 in group II). The incidence of enteric complications was 6 in group I and 5 in group II, which was statistically insignificant $(\mathrm{p}>0.05)$. 


\section{Discussion}

Early nutrition support has been advocated over the years in rapid recovery of critical patients on controlled ventilation. In the present study, the implementation of a voluntary nutrition support protocol significantly decreased the time to the initiation of nutrition support across all patients by over fifteen hours.

Maximum patients in protocoled group received EN in early hours of ICU admission. In most of the ICUs there is a propensity for mechanically ventilated patients to remain fasting or take liquid diet. Franklin et $\mathrm{al}^{16}$ observed that $22 \%$ of all patients admitted to a hospital received nothing orally for $>3$ days, with a mean of 5.2 days and a maximum of 16 days.

In a study measuring the effectiveness of enteral nutrition with an infusion protocol, Spain et al ${ }^{17}$ found that physicians' were unwilling to use the protocol leading to decreased efficacy. A prolonged period of two to three years was required to fully implement the protocols into practice. To overcome this reluctance continued medical education emphasizing protocol strategy should be provided to all physicians and ICU staff. Stigmatic approaches are primarily responsible for receiving inadequate enteral feeding. Inability to give early enteral feeding was shown in one study by Franklin et al to ${ }^{16}$ be due to concerns for ileus (29.7\% of cases), perioperative dietary management ( $28.8 \%$ of cases), and diagnostic tests $(7.7 \%)$.

In our study, the patients were allocated randomly into two groups (I and II). Mechanical ventilation in group I patients i.e. in whom nutrition support protocols were followed was $10.1( \pm 3.6)$ days and in group II patients it was $18( \pm 4.1)$ days. The duration was reduced in group I patients by almost 7 days $(\mathrm{p}<0.001)$. In a similar study by Zaloga et $\mathrm{al},{ }^{18}$ they concluded that there were no significant changes in the time to feeding, percentage of targeted calories administered, ICU stay, hospital stay, or mortality rate. However, they noted a trend $(\mathrm{p}=0.11)$ towards reduction in mechanical ventilation in protocolized group similar to our study.

ICU stay in group I was $17.26( \pm 5.3)$ days while in group II it was 25.11 $( \pm 8.5$ ) days, (p-value $<0.001)$ which showed a reduction of about 8 days. The total duration in hospital in group I patients was $22.7( \pm 7.5)$ days while in group II patients it was $31.9( \pm 9.8)$ days which implies there was a decrease in overall hospital stay in the group in which nutrition protocols were followed. Regarding mortality rates a total of 7 patients died in group I patients (28\%) while 12 patients out of group II (48\%) died within 60 days which showed overall low mortality in group I patients. In a large cluster randomized study by Martin et al, ${ }^{19}$ ICUs that followed aggressive enteral feeding protocols, showed decreased hospital stay by 10 days, and reduced mortality by $10 \%$ compared with control patients.

In our study, the time to nutrition initiation after admission in ICU was $41.2( \pm 8.5) \mathrm{hrs}$ in group I while it was $57.1( \pm 18.8)$ hours in group II which showed a reduction of about 16 hours. Heyland et $\mathrm{al}^{4}$ in a similar study found that hospitalized patients with a feeding protocol had early initiation of EN (41.2 hours from admission to ICU vs $57.1,(\mathrm{P}=.0003)$ compared with non protocolized ICUs. Mackenzie et $\mathrm{al}^{20}$ in their study stated that the ICU patients who received the targeted energy requirements increased triple fold after implementation of the protocol $(\mathrm{p}<.001)$. The implementation of an enteral tube feeding protocol in the Arabi et $\mathrm{al}^{21}$ study showed a significant improvement in those receiving gastric feeds. There were smaller amounts of gastric residual volumes and episodes of vomiting reported with those on the protocol when compared to the controls.

Regarding complications; septicemia, chest related infections and urinary tract infections was higher in group II patients $(\mathrm{p}<0.05)$ while both the groups had similar incidence of enteric complications. All the studies supported our findings thus emphasizing that protocol approach is undoubtedly effective, showing on a global scale that ICUs that have a feeding protocol start the feeding sooner, have a lesser ICU and in-hospital mortality than those with no protocol.

\section{Study Limitations}

The study could have been done with a higher sample size involving more number of test and control patients. This study could have been more informative and easy to carry out with a dedicated nutritionist trained in critical care setting. We, therefore, suggest further studies to include the same. The staff in critical care settings is posted shift wise so the observations might vary from person to person.

\section{Conclusion}

Thus it was concluded that patients in whom nutrition support protocols were followed had early weaning from ventilator, spent less time in ICU as well as hospital, had lesser complications with low mortality and hence found to be more cost-effective approach.

\section{Conflict of Interest: None}

\section{References}

1. Merritt R. The American Society for Parenteral and Enteral Nutrition. Nutrition Support Practice Manual. 2nd Edition. 2005.

2. Giner M, Laviano A, Meguid MM, Gleason JR. In 1995 a correlation between malnutrition and poor outcomes in critically ill patients still exists. Nutrition. 1996;12(1):23-29.

3. Kattelmann KK, Hise M, Russell M, Charney P, Stokes M, Compeer C. Preliminary evidence for a medical nutrition therapy protocol: enteral feedings for critically ill patients. J Am Diet Assoc. 2006;106(8):1226-1241.

4. Heyland DK, Dhaliwal R, Drover JW, Gramlich L, Dodek P. Canadian clinical practice guidelines for nutrition support in mechanically ventilated, critically ill adult patients. JPEN J Parenter Enteral Nutr. 2003;27(5):355-373. 
5. Marik PE, Zaloga GP. Early enteral nutrition in acutely ill patients: a systematic review. Crit Care Med. 2001;29(12):2264-2270.

6. Barr J, Hecht M, Flavin KE, Khorana A, Gould MK. Outcomes in critically ill patient before and after the implementation of an evidence-based nutritional management protocol. Chest. 2004;125:1446-1457.

7. American Society for Parenteral and Enteral Nutrition Board of Directors and the Clinical Guidelines Task Force. Guidelines for the use of parenteral and enteral nutrition in adult and pediatric patients. JPEN J Parenter Enteral Nutr. 2002;26(suppl):1-138.

8. Ibrahim EH, Mehringer L, Prentice D, et al. Early versus late enteral feeding of mechanically ventilated patients: results of a clinical trial. JPEN J Parenter Enteral Nutr. 2002;26(3):174-181.

9. Binnekade MJ, Tepaske R, Bruynzeel P, Mathus-Vliegen EMH, de Haan RJ. Daily enteral feeding practice on the ICU: attainment of goals and interfering factors. Crit Care Med. 2005;9:218-225.

10. Heyland DK, MacDonald S, Keefe L, Drover JW. Total parenteral nutrition in the critically ill patient: a meta-analysis. JAMA. 1998;280:2013-19.

11. Guenter P, Hicks RW, Simmons D, et al. Enteral feeding misconnections: a consortium position statement. Jt Comm J Qual Patient Saf. 2008;34:285-292.

12. Bankhead RR, Fang JC. Enteral access devices. In: Gottschlich MM, ed. The A.S.P.E.N. Nutrition Support Core Curriculum: A Case-Based Approach-The Adult Patient. Silver Spring, MD: American Society for Parenteral and Enteral Nutrition; 2007:233-245.

13. Malone AM, Seres DS, Lord L. Complications of enteral nutrition. In: Gottschlich MM, ed. The A.S.P.E.N. Nutrition Support Core Curriculum: A Case-Based Approach-The Adult Patient. Silver Spring, MD: American Society for Parenteral and Enteral Nutrition. 2007:246-263.

14. Roberts SR, Kennerly DA, Keane D, George C. Nutrition support in the intensive care unit: adequacy, timeliness, and outcomes. Crit Care Nurse. 2003;23(6):49-57.
15. Carr CS, Ling KDE, Boulos P. Randomized trial of safety and efficacy of immediate postoperative enteral feeding in patients undergoing gastrointestinal resection. BMJ. 1996;312:869-871.

16. Franklin G, Mcclave SA, Lowen C. Physician delivered malnutrition: why do patients remain NPO or on clear liquids in a university hospital setting. JPEN J Parenteral Enteral nutr. 2006;30:S32-S36.

17. Spain DA, McClave SA, Sexton LK, Adams JL, Blanford BS, Sullins ME, Owens NA, Snider HL. Infusion protocol improves delivery of enteral tube feeding in the critical care unit. JPEN J Parenter Enteral Nutr. 1999;23(5):288-292.

18. Zaloga GP, Bortenschlager L. anorexia protocolis. Chest. 2004;125(4):1195-1197.

19. Martin CM, Doig GS, Heyland DK, Morrison T, Sibbald WJ. Southwestern Ontario Critical Care Research Network. Multicentre, cluster-randomized clinical trial of algorithms for critical care enteral and parenteral therapy (ACCEPT). Can Med Assoc J. 2004;170:197-204.

20. Mackenzie SL, Zygun DA, Whitmore BL, Doig CJ, Hameed SM. Implementation of a nutrition support protocol increases the proportion of mechanically ventilated patients reaching enteral nutrition targets in the adult intensive care unit. JPEN J Parenter enteral nuts. 2005;29(2):74-80.

21. Arabi Y, Haddad S, Sakkijha M, Shimemeri AA. The impact of implementing an enteral tube feeding protocol on caloric and protein delivery in intensive care unit patients. JPEN J Parenter Enteral Nutr. 2004;19(5):523-530.

How to cite this article: Singh $S$, Ambasta $S$. The effect of nutritional protocols on mechanically ventilated patients in intensive care unit: A randomised controlled study. Indian J Clin Anaesth. 2018;5(3):378-382. 